\title{
ARTikertuz, ¿qué conocimiento generamos a partir de la relación pedagógica entre profesorado?
}

\author{
ARTikertuz, what knowledge is generated from the pedagogical \\ relationship between teachers?
}

\author{
Estibaliz ABERASTURI. Universidad del País Vasco, EHU/UPV (España). \\ estitxu.aberasturi@ehu.es \\ Jose Miguel CORREA. Universidad del País Vasco, EHU/UPV (España). \\ jmcorreagorospe@gmail.com \\ Regina GUERRA. Universidad del País Vasco, EHU/UPV (España). \\ regina_ramone@hotmail.com
}

Resumen: Este artículo se basa en la experiencia que el grupo Elkarrikertuz lleva a cabo dentro del proyecto de ivvnvestigación ARTikertuz (EHU 15/24). En él, se investiga sobre el conocimiento que se genera en las sesiones donde lxs participantes, entre lxs cuales se encuentran lxs investigadores, comparten sus experiencias y cuestionan sus propias prácticas docentes y las de sus compañerxs. Se abordan cuestiones curriculares y se trabaja en torno a la temática de la educación artística ya que se piensa que sus metodologías facilitan la comunicación y el intercambio de reflexiones.

La metodología que se propone es la narrativa, usando el método visual, ya que permite indagar las relaciones pedagógicas desde su complejidad. Buscamos conocer las relaciones que tienen las personas con otros individuos y de qué manera estas relaciones posibilitan o obstaculizan la generación de conocimiento. Se centra en la construcción del conocimiento y en su representación: cómo nos narramos y relatamos lo que hacemos.

Elegiremos imágenes de las sesiones, las analizaremos y pasaremos por las diferentes fases de análisis de los datos para abordar la cuestión de investigación a través de la discusión y aportar las conclusiones. 
Palabras clave: relación pedagógica, comunidad de práctica, investigación narrativa, práctica docente, metodologías visuales.

\begin{abstract}
This article is based on the experience that the research group Elkariketuz carried out at the meetings of the project UPV. ARTikertuz. In it, it seeks to investigate the knowledge generated in the sessions where the participants, the same researchers, share their experiences and question their own teaching practices and those of their fellows. Curricular issues are addressed and it works around the theme of art education as it is thought that it's methodologies facilitate communication and the exchange of reflections.
\end{abstract}

The proposed method is visual, allowing investigate the pedagogical relations since its complexity. It seeks to understand the relationships that people have with other individuals and how these relationships enable or hinder the generation of knowledge (collective or individual). It focuses on building knowledge and representation: how we narrate and we report what we do.

We choose images of the sessions, we will analyze them and we will pass through the various stages of data analysis to address research through discussion and provide the findings.

Keywords: pedagogical relationship, community of practice, narrative research, teaching practice, visual methodologies.

\title{
Introducción
}

La investigación (Universidad del País Vasco EHU-UPV, 2015-2017-15/24) en la que actualmente estamos implicadxs busca dar respuesta a diversas preguntas, pero nos detenemos en una de ellas para su estudio: ¿qué conocimiento generamos a partir de la relación pedagógica entre profesorado?

El grupo de trabajo ARTikertuz está formado por maestros y maestras de educación infantil, primaria, secundaria y profesorado universitario y de investigación. Tiene como objetivo el encuentro, la relación con el Otro, generar conocimiento que nos permita transformar nuestra práctica docente. La finalidad del grupo es revisar el significado y sentido de la expresión visual y artística, poner en relación dilemas y cuestiones a abordar para el desarrollo de propuestas a partir del intercambio de experiencias con el grupo, y proponer y llevar a la práctica nuevas experiencias educativas, y reflexionar y valorar los resultados.

Comenzamos a reunirnos en el curso escolar 2014/2015, una vez al mes, por las tardes en sesiones de 2 horas aproximadamente, y continuamos este curso 2015/16. Las sesiones las grabamos en audio para transcribirlas y redactar el acta. 
Para este artículo nos detenemos en las sesiones realizadas en el curso pasado. Fueron cinco sesiones; en la primera nos centramos principalmente en presentarnos y conocernos, y en la última, en un estudio de los proyectos a realizar el próximo curso. Es por ello que elegimos las otras tres sesiones para su análisis.

El método que proponemos es visual, ya que nos interesa indagar en las relaciones pedagógicas desde su complejidad y consideramos que uno de los puntos fuertes de los métodos visuales en particular descansa en la naturaleza inevitablemente abierta de la investigación (Banks, 2010, p. 86). Buscamos conocer las relaciones que tienen las personas con otros individuos y de qué manera estas relaciones posibilitan o obstaculizan la generación de conocimiento (colectivo o individual). Nos centramos en la construcción del conocimiento y en su representación: cómo nos narramos y relatamos lo que hacemos. ¿Lo ponemos en relación y reflexionamos de manera crítica?

Para el estudio de los datos cada investigador elige una imagen de cada sesión (tres en total), imágenes que considere evocadoras; además, elabora un texto narrativo que acompaña y amplía la idea que quiere desarrollar. Estos relatos visuales y escritos se cruzaran entre los tres investigadores y se extraen temas o conceptos relevantes para dar respuesta a la pregunta del estudio. Partimos de la idea de que la relación subjetiva con representaciones visuales permite otra aproximación al tema de estudio.

Entendemos que es necesario y muy relevante unir los procesos de investigación a los de la docencia, no sólo desde la universidad, sino desde la escuela como mejora significativa de la calidad y mejora. Desde este trabajo esperamos aportar propuestas y estrategias de relación que permita la transformación relevante en la universidad y la escuela, a partir de este espacio de relación entre profesorado.

\section{Generar conocimiento:}

Analizar cómo aprendemos y generamos conocimiento podría ayudarnos a desarrollar un discurso compartido acerca de la formación. En el caso de la educación, tal vez el concepto fundamental es el del conocimiento en sí mismo, qué conocimiento generamos y para qué. Considerando que el conocimiento se genera en grupo, la pregunta sería cómo definimos a partir del encuentro con los Otros este conocimiento. Cada una de las orientaciones que tengamos respecto al conocimiento determinará o justificará la práctica educativa que propongamos. De manera que cuando optamos por una comunidad de práctica para la investigación, partimos de una orientación concreta sobre el conocimiento, siempre situado y compartido.

La relación con el Otro:

La tradición localiza al conocimiento dentro de las mentes de los individuos singulares. Sin embargo, cuando se entiende que esta posición no favorece a la 
comunidad educativa, es donde una posición socioconstruccionista recobra sentido, donde se entiende el conocimiento no como producto de las mentes individuales sino de las relaciones comunitarias. Nuestra intención es estudiar cómo aprendemos a partir de la relación en la que aprendemos todos y todas. Se trata de indagar cómo aprendemos a partir de las relaciones pedagógicas con la escuela.

A partir del encuentro en grupo proponemos guiar y acompañar a los participantes, en el proceso de reflexión identitaria. Y es aquí donde esta investigación marca la diferencia, ya que las personas investigadoras, participamos de manera activa en estos encuentros, dando voz a nuestras experiencias y creando una red de relaciones. $\mathrm{Y}$ es esta misma red la que permite hacer del otro, no un objeto, sino un compañero de diálogo (Koepping, 1987, p. 28) (Flick, 2012, p. 158). Aunque consideremos al Otro como un compañerx de diálogo, es importante matizar aquí una distinción entre el diálogo y lo dialógico:

Lo dialógico, a diferencia de lo dialéctico o del diálogo, explora el sujeto, su multiplicidad, la necesidad que siente del otro, pues la noción de ser conecta con el ser para otro. Ser, por tanto, significa comunicarse dialógicamente con el otro. La construcción del sujeto, la construcción de su formación, la historia de su gestación cultural se ha entrelazado con los otros comunicantes (Virginia Ferrer, 1995, p. 171)

Es por eso que consideramos la comunicación dialógica como una oportunidad para poner sobre la mesa las experiencias de los participantes y compartir esos momentos en común cuestionándolos y transformándolos en conocimiento. Ese conocimiento nos sirve para reflexionar sobre nuestras identidades docentes, las prácticas educativas (tanto en los centros escolares como en la universidad) y también para generar dinámicas para las propias sesiones del grupo. Transformar el conocimiento situado de la experiencia individual en un conocimiento mas complejo gracias a la comunicación dialógica. Pero también transformar a lxs docentxs e investogadorxs que nos encontramos en el grupo, transformando nuestra manera de pensar, de actuar y contemplar la práctica docente para que se pueda dar lugar al aprendizaje y al cambio. Al ver las necesidades del grupo y la implicación de los participantes en las sesiones esta se convirtió en una comunidad de práctica que genera conocimiento asumiendo su propia incertidumbre.

The concept of community of practice does not exist by itself. It is part of a broader conceptual framework for thinking about learning in its social dimensions. It is a perspective that locates learning, not in the head or outside it, but in the relationship between the person and the world, which for human beings is a social person in a social world. (Etiene Wenger) ${ }^{1}$

Overtime, ahistoryoflearningbecomesaninformalanddynamicsocialstructureamong the participants, and this is what a community of practice is. (Etiene Wenger Íbidis.)

1. http://wenger-trayner.com/wp-content/uploads/2012/01/09-10-27-CoPs-and-systems-v2.01.pdf; Communities of practice and social learning system recuperado el 30/03/2016 a las 12:14pm 


\section{Método}

Para el análisis de los datos nos basamos en la investigación narrativa. Este modelo de investigación, permite que desde un punto de vista cualitativo nos podamos acercar a un fenómeno social desde la perspectiva de los actores involucrados en el mismo. Se trata de contar sus historias con el fin de completar una narración que nace desde el mismo objeto de estudio y que tiene como eje las experiencias del propio profesorado. Como dicen Connelly y Clandinin (1995) el estudio de la narrativa es el estudio de la forma en el que los seres humanos experimentamos el mundo; los investigadores narrativos buscan describir esas vidas, recoger y contar historias sobre ellas, y escribir relatos de la experiencia.

En esta investigación compartimos la necesidad de realizar una observación participante, ya que cómo decíamos anteriormente, esta investigación se caracteriza porque lxs investigadores participamos de forma activa. "La observación participante se definirá como una estrategia de campo que combina simultáneamente el análisis de documentos, la entrevista a respondientes e informantes, la participación directa y la observación, y la introspeción" Denzin (1989) en Flick (2012, p. 154). Para llevarla a cabo, se realizará la grabación de las sesiones de trabajo, transcripción y análisis de las temáticas emergidas. En esta ocasión, para éste análisis hemos optado por el método visual como técnica de recogida de datos. Para abordar las temáticas emergidas optamos por seleccionar tres imágenes de cada sesión cada unx de nosotrxs y escribir un relato narrativo que lo acompañara. Cruzamos estos documentos y los ponemos en relación para el análisis posterior.

En las reuniones las experiencias se conforman a partir del significado emergido del intercambio con el grupo (Denzin, 1997) y la investigación se hace en y sobre esa participación; es entonces fundamental reflejar esa condición a través de una escritura dialógica, compuesta por relatos que mezclan nuestra voz como investigadores con la de las personas del grupo, a través de fotografías, entrevistas transcritas y pitas de audio, escuchando, observando y sintiendo desde el campo de estudio.

Los encuentros formativos con el grupo de maestras será la clave para construir un relato en donde responder a la pregunta: cómo se genera el conocimiento y cómo se gestiona este conocimiento desde un proceso de formación considerado como un proceso de creación compartida.

En busca de una metodología visual crítica a la hora de exponer los textos y las imágenes, el uso de estas a modo de foto-ensayos nos parece interesante ya que pueden tener dos efectos: el analítico y el evocativo. Según Gillian Rose (2012) los foto-ensayos no son un método de investigación per se, pero es un método particular para transmitir los hallazgos del proyecto de investigación a la audiencia. Para ello, según Rose, es crucial considerar la relación entre la fotografía y el texto. En este caso, los textos describen las sensaciones y las experiencias que sucedieron 
en esa escena, las razones de que las eligieran o las crearan, o las ideas y conceptos que afloran en las sesiones. Una vez leídos los textos y analizado las imágenes, nos damos cuenta de que no solamente las imágenes elegidas por un/a de lxs investigadores hace referencia a su texto, sino que además sirve de complemento o contrapunto con lo que las otras imágenes y textos dicen, por lo que en cierta manera los textos (las voces de lxs investigadores) y las imágenes se cruzan dialógicamente para dar respuesta a la pregunta de investigación: ¿qué conocimiento generamos a partir de la relación pedagógica entre profesorado?

Fases de la investigación:

\begin{tabular}{|c|c|c|c|}
\hline FASE 1 & FASE 2 & FASE 3 & FASE 4 \\
\hline & Relato Visual: & \multirow{10}{*}{$\begin{array}{l}\text { - Temáticas } \\
\text { emergentes } \\
\text { - Análisis } \\
\text { visual y del } \\
\text { relato }\end{array}$} & \multirow{10}{*}{ - Discusión } \\
\hline Sesión 2 & Investigador $1(\mathrm{~J})$ & & \\
\hline Observación participante & Investigador $2(\mathrm{R})$ & & \\
\hline & Investigador $3(\mathrm{E})$ & & \\
\hline \multirow[b]{2}{*}{ Observación participante } & $\begin{array}{l}\text { Relato Visual: } \\
\text { Investigador } 1(\mathrm{~J})\end{array}$ & & \\
\hline & $\begin{array}{l}\text { Investigador } 2(\mathrm{R}) \\
\text { Investigador } 3(\mathrm{E})\end{array}$ & & \\
\hline \multirow{4}{*}{$\begin{array}{l}\text { Sesión } 4 \\
\text { Observación participante }\end{array}$} & Relato Visual: & & \\
\hline & Investigador $1(\mathrm{~J})$ & & \\
\hline & Investigador $2(\mathrm{R})$ & & \\
\hline & Investigador $3(\mathrm{E})$ & & \\
\hline $\begin{array}{l}\text { PREGUNTA DE } \\
\text { INVESTIGACIÓN }\end{array}$ & \multicolumn{3}{|c|}{$\begin{array}{l}\text { ¿Qué conocimiento generamos a partir de la relación } \\
\text { pedagógica entre el profesorado? }\end{array}$} \\
\hline \multicolumn{4}{|c|}{ Conclusiones } \\
\hline
\end{tabular}


Fase 3: Temáticas emergentes y análisis visual y del relato.

A partir del relato visual de cada investigación y la observación participante, recogemos los temas emergentes y realizamos el análisis que resumimos en la siguiente tabla:

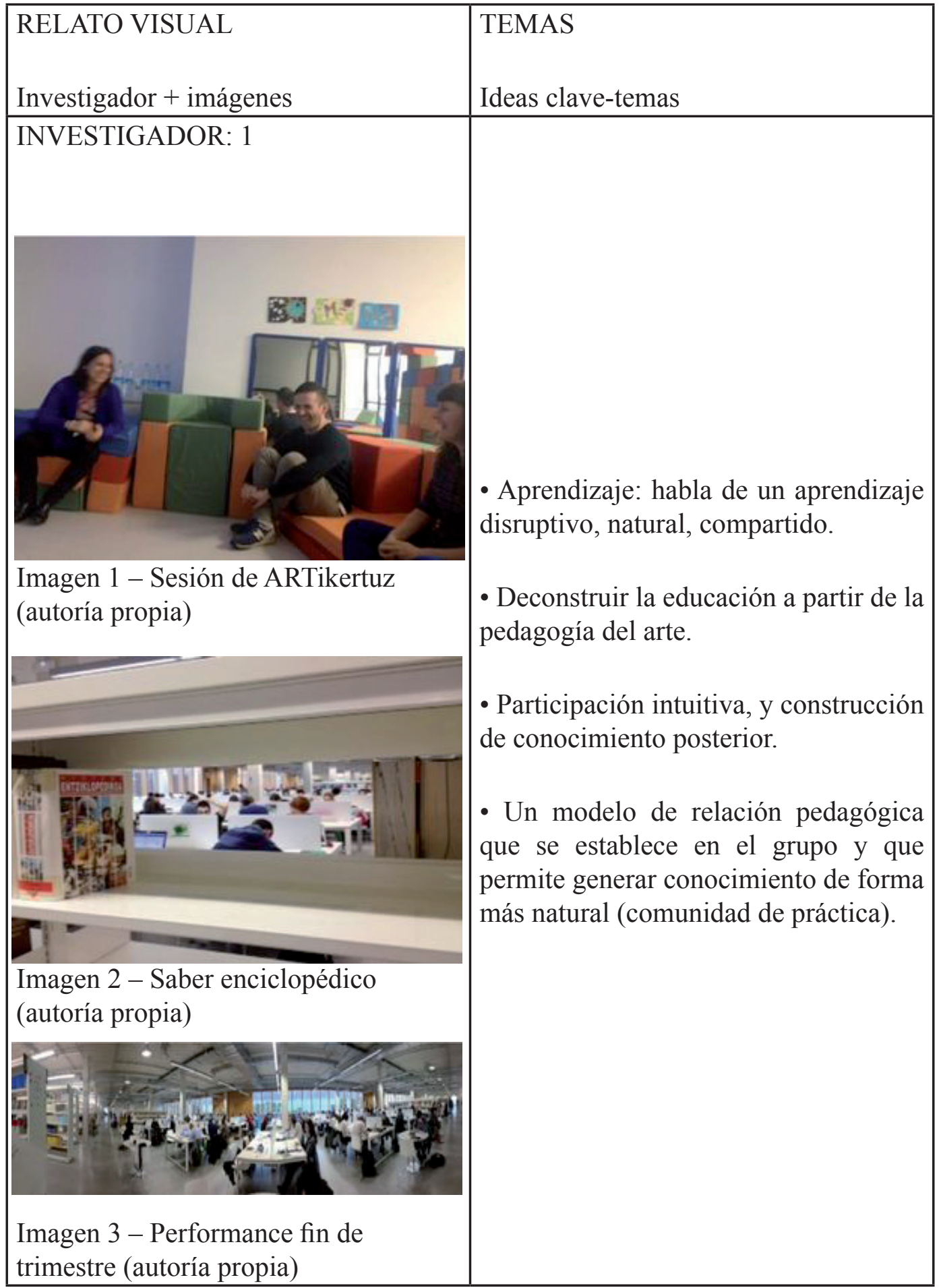




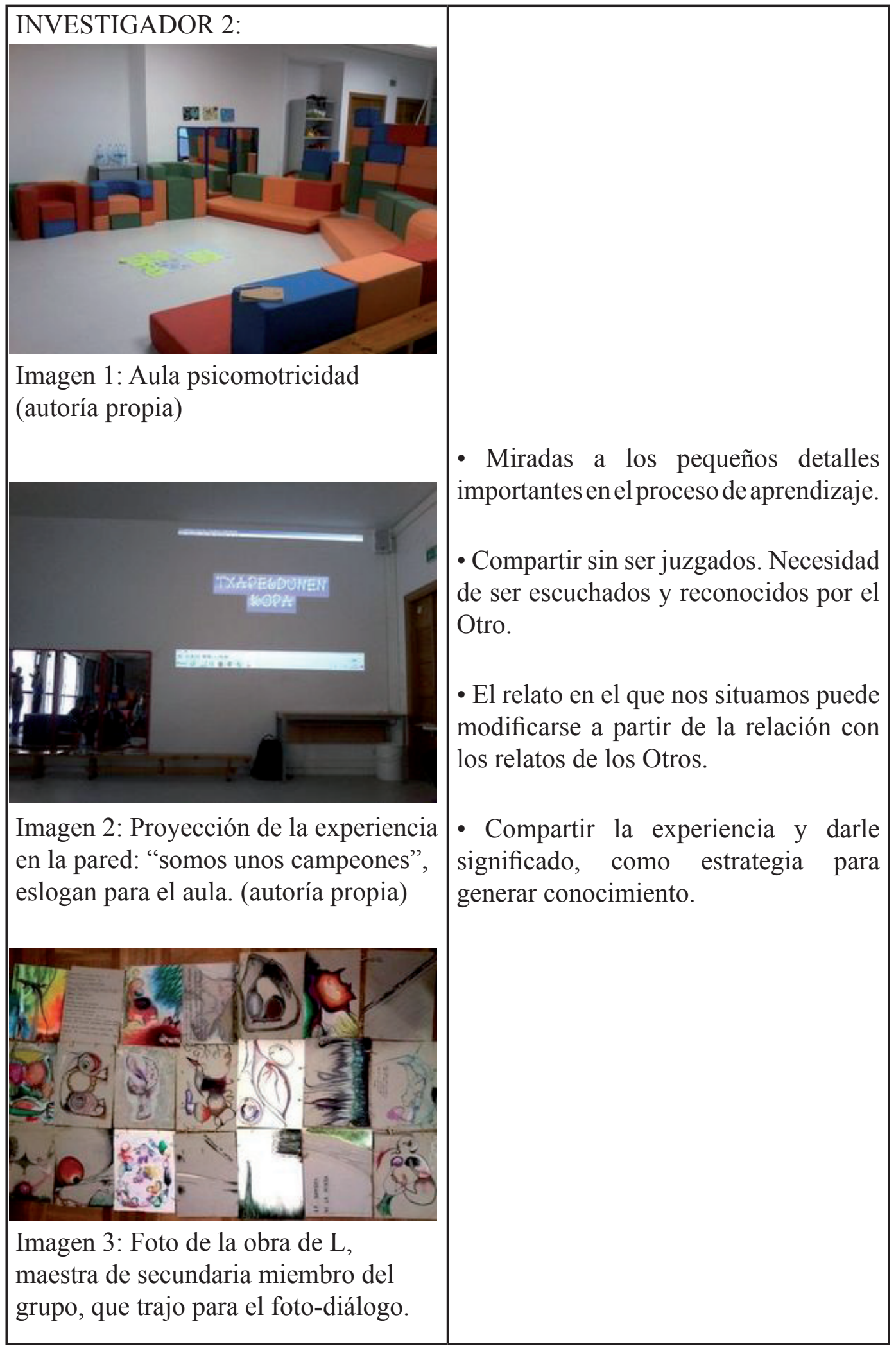




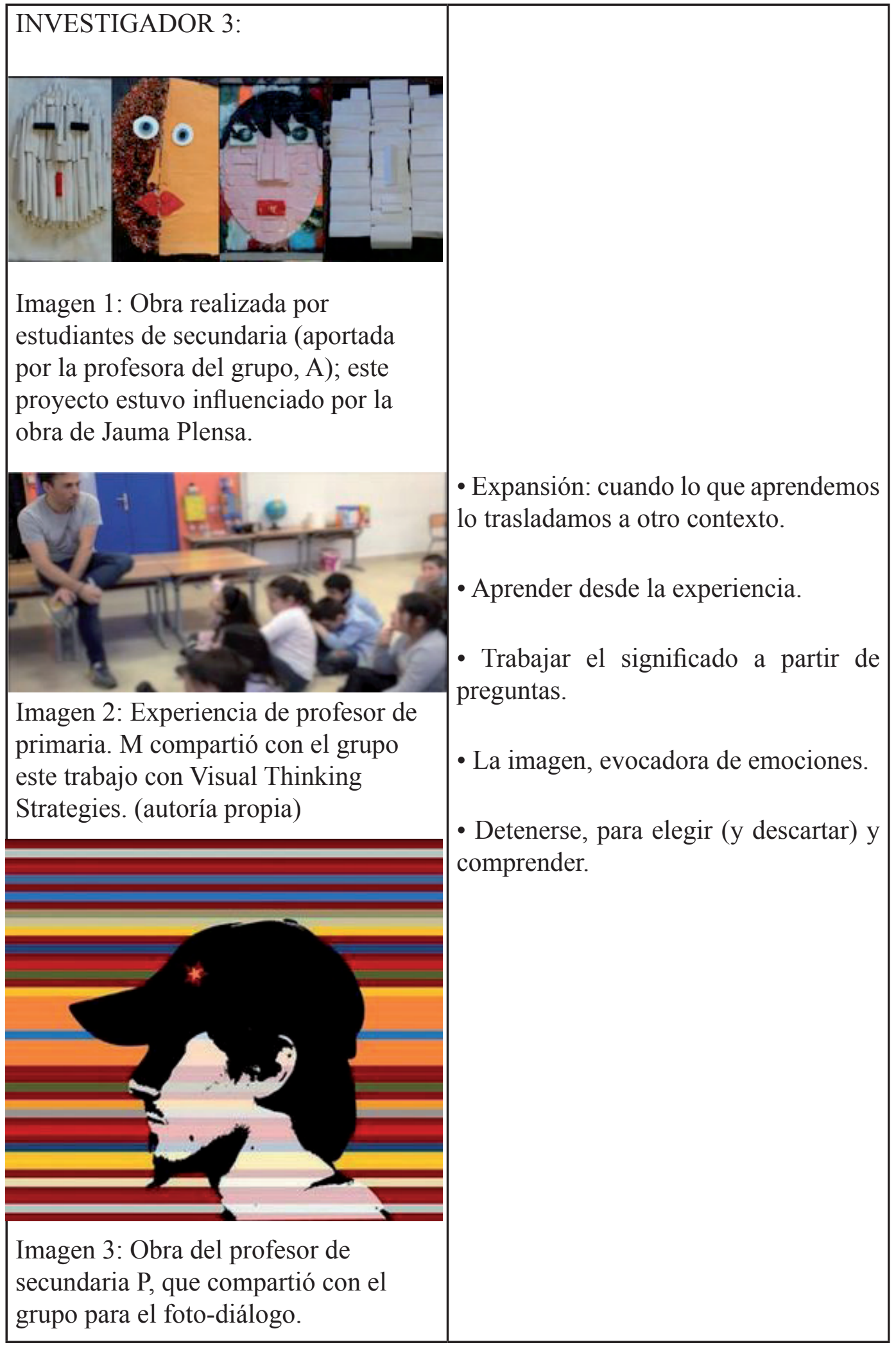


Fase 4: Discusión de los resultados de las narraciones.

De las temáticas que emergieron de las narraciones que los investigadores crearon para este artículo, se rescatan cuatro que se dividen en conceptos que tienen que ver con el conocimiento generado a partir de los encuentros del grupo en las sesiones.

La manera de narrarlo está pensada desde el punto de vista de la comunicación dialógica, en la que las experiencias de los demás constituyen en nosotros nuevas maneras de cuestionarnos y transformarnos tanto de manera profesional como personal.

Según los principios de diálogo, la interacción entre yo y el otro, a través del cual el yo se aproxima a sí mismo de otra manera; es decir, re-conociéndose así mismo como nuevo a través de a mediación de un doble ajeno (...) Este suceso dialéctico provoca una transición de la individualidad a la sociabilidad, de la existencia privada o solitaria a la comunidad y al tener en común. Éste es el telos de la comunicación de un devenir dialéctico. (Chang, 1996, p. 44 en Ellsworth, 2005, p. 90)

Las imágenes también aparecerán de manera dialógica las unas con las otras. Al principio la intención era crear narraciones a partir de imágenes evocadoras y que cada narración correspondiera a una imagen en concreto. Una vez analizadas como imágenes y también a modo de representación visual de la idea detrás de la narración, vemos que comparten muchas de las temáticas emergentes en las narraciones y que por tanto dialogan de manera contrapuestas o complementarias. Nos vemos obligados a justificar la superación de la cantidad de imágenes establecidas por las normas de la revista, ya que estas imágenes son las que sirven de origen al artículo y disminuir su cantidad o obviar algunas imágenes solo descompensaría la investigación.

Así mismo, las narraciones o voces de los investigadores también dialogarán entre ellas de manera anacrónica en relación a las sesiones ya que lo que prima en este diálogo son los temas que constituyen parte del conocimiento generado en este grupo. Se expondrán en tablas de manera que se distingan del desarrollo de la discusión.

1.Sentido de pertenencia: Comunidad de práctica: (Véanse las imágenes 1 y 2 de manera contrapuesta)

El primer grupo de temas que emergen desde las narraciones de los investigadores se centra en torno al concepto del grupo de Artikertuz y su pertenencia a él. Teniendo en cuenta la razón por la que surgieron estos encuentros, se ve una clara evolución desde lo que en principio sirvió como un grupo de discusión en la que diferentes docentes de educación primaría, secundaría y universitaria compartían sus experiencias y dudas en torno a la práctica educativa, hasta la formación de una comunidad de práctica, donde el conocimiento que se genera a partir de 
estas experiencias sirve para ir más allá. Los investigadores se sinceran sobre sus sensaciones y problematizan sus roles dentro del grupo, pero no solo de una manera profesional, si no también personal.

Se habla desde las sensaciones y las intuiciones a la hora de experimentar las sesiones al igual que el sentimiento de pertenencia y el rol de cada unx en las reuniones.

Los temas que han salido vinculados a sentido de pertenencia son:

- El aprendizaje: se habla de un aprendizaje disruptivo, natural, compartido que permite deconstruir la educación a partir de la pedagogía del arte. Aunque la participación en el grupo sea muchas veces poco clara, sí se detecta un componente intuitivo por parte de los participantes, que perciben que puede resultarles interesante pero no podrían definir el por qué. Quizá sea, porque la construcción de conocimiento es posterior, tras la participación.

-Un modelo de relación pedagógica: que se establece en el grupo y que permite generar conocimiento de forma más natural (comunidad de práctica). Compartir sin ser juzgados. Necesidad de ser escuchados y reconocidos por el Otro.

J: "La primera sensación que tuve al estar sentado compartiendo conversaciones sobre pedagogía del arte fue de intrusismo. Estos encuentros con profesores siempre me han ofrecido nuevos puntos de vista sobre la educación y un marco interesante de relaciones para transitar por otras veredas alejándome de los caminos rutinarios por los que estoy acostumbrado a circular. La naturalidad del vínculo que nos ha llevado a constituirnos como comunidad de práctica, ha sido otra motivación en este proceso de compartir la práctica avala ciertas garantías".

E: "Considero una fortaleza iniciar compartiendo nuestras experiencias educativas, ofreciendo ejemplo y exponiéndonos al juicio y valoración de los Otros".

En este sentido compartimos lo que nos dice Carla Padró cuando habla de salirse del marco pedagógico "o sea, de las normas, las expectativas y las representaciones de los sujetos que aprenden-enseñan, es un acto político que nos permite releernos desde otros lugares. También nos ayuda a re-visitar nuestros discursos y prácticas pedagógicas" (Padró, 2011, p. 12). 
$\mathrm{J}$ : "Como investigador también he mantenido atenta la mirada y la escucha en cómo se constituía el grupo, qué relaciones se establecían, cómo se organizaban las sesiones, qué se ponía en juego, como era la colaboración en el grupo, qué modelo de profesor o profesora querían ser, cómo estaría influyéndoles esta experiencia de ARTikertuz. La comodidad de pertenecer a un grupo donde muchas cosas (relaciones, planificación, dirección) las aportaba $\mathrm{E}$, no ha evitado problematizarme sobre qué estaba yo haciendo allí tanto como profesor y como investigador y qué podía yo aportar a un grupo donde en cierta manera me sentía como extraño, atrevido, intruso...

E: "Para generar conocimiento, creo que las preguntas son fundamentales. Es por ello que observamos en esta sesión las experiencias a partir de estas preguntas: ¿Qué aportación le hacemos al Otro? ¿Qué aprendemos de la experiencia del Otro?¿Qué nos enseña el texto teórico, nos ayuda a mirar la experiencia desde otro lugar?"

Como venimos diciendo a lo largo del artículo, y citando a Freire en palabras de Tadeo da Silva (2011, p. 72), "el acto de conocer no es para un acto aislado, individual. Conocer implica intercomunicación, intersubjetividad (...) Esta intersubjetividad del conocimiento permite a Freire concebir el acto pedagógico como un acto dialógico".

R: "Siempre intentamos crear ambientes y espacios de intercambios de experiencias y de reflexión, un lugar para el diálogo, donde todxs estamos a un mismo nivel".

J: "Risas de complicidad en el encuentro, de conexión y de colaboración, quizá una relación con el conocimiento vivo, no enciclopédico, compartido y una representación del mismo fluyendo, liberando y dándonos energía Esta puede ser la definición de una relación pedagógica que permite generar conocimiento. La imagen del cambio y disruptividad pedagógica, sobre todo si la relacionamos con la imagen 2 y $3 "$.

Puede que desde el campo de la educación y la práctica del arte se genere una manera de relacionarse con el conocimiento natural como nos dicen Barone y Eisner (2012): "Qualitative experience is experience by sensory informartion. Art based research is inherently qualitative in character", considerándolo como una aportación relevante a la educación. 
2. Ser dueños del proceso de aprendizaje: (Véanse las imágenes 3 y 5 de manera contrapuesta)

En este bloque se rescatan fragmentos de los relatos que abarcan desde la manera en la que una docente deja el mando del proceso de aprendizaje en sus alumnos, hasta metáforas visuales de las realidades pedagógicas cotidianas.

Los temas que han emergido relacionados con el proceso de aprendizaje son:

-Expansión: cuando lo que aprendemos lo trasladamos a otro contexto. Aprendizaje del profesorado que permite la expansión a su campo, añadiendo y mejorando su propio trabajo a partir de lo compartido en el grupo de trabajo.

-Aprender desde la experiencia es una de las señas de identidad del grupo; pero para trabajar el significado se hace a partir de preguntas, que nos llevan a nuevas cuestiones.

J: "mi posición en este grupo está motivada, en gran medida, por el deseo de comprender, compartir y aprender ciertas estrategias y enfoques que posibilitan el cambio desde una especial relación que intuyo que la pedagogía del arte posibilita establecer con el curriculum".

El carácter extraescolar y la poca atención que obtiene el arte y su pedagogía en las instituciones escolares hace que desde otras perspectivas cobre un valor adicional, como dicen Barone y Eisner (2012) "the power to lure the audience into an alternative experiencing of the world suggests the capacity of the arts for doing that which other discursive formations cannot".

$\mathrm{R}$ : "J (docente de primaria) contó que un día se le ocurrió poner el video de Jauma Plensa en su clase, y que sus alumnxs respondieron positivamente a este. Entonces pasó algo, la actividad no terminó de cuajar, porque lxs alumnxs no habían entendido bien la propuesta. Entonces, la docente decidió cambiar de estrategia e hizo que las necesidades y procesos de aprendizaje del alumnado cogieran protagonismo en el proyecto. Pasó de marcar las direcciones y las maneras de abordar el proyecto, a servir de ayuda al alumnado haciendo que fueras ellxs quienes marcasen los ritmos y el contenido en él.

El caso de $\mathrm{J}$ muestra la implicación de la docente, que viendo cómo su práctica docente no consigue llevarse a cabo, deja el poder de la actividad en manos del alumnado y crea, de una manera no intencionada, una implicación directa entre sus 
estudiantes y los contenidos que ella quería trabajar en el aula. Como dice Maria Acaso (1998) "convirtió el proceso del aprendizaje en un proceso activo de tal manera que el alumnado se sentía dueño de su propio proceso de aprendizaje" y eso es quizás lo más importante de este relato: el empoderamiento de una docente que cede su poder y aprende de sus alumnos, y que mientras relata su experiencia al grupo en las sesiones se da cuenta de su propio proceso de aprendizaje como docente.

J: "La Imagen 3, que he titulado Performance fin de trimestre, en tanto que registro y representación de las relaciones pedagógicas cotidianas (Gomez y Ardevol, 2011), me permite reflexionar sobre las paradójicas relaciones que mantenemos con el conocimiento (...) Fue un instante que retrata en el elegante edificio de la biblioteca de nuestro campus, un relato que perpetúa la conocida relación con el conocimiento instalado en nuestras prácticas educativas: memorización-repetición-vómito, motivada por la proximidad de los exámenes, momento crítico para dar cuenta de un tipo de conocimiento estanco, aislado, no circulante".

Este relato tiene mucho que ver con la idea de la educación industrial que María Acaso (2014) utiliza a modo de metáfora para definir una educación que esta estancada en la palabra del profesor, en la verdad inamovible que está detrás de sus lecciones y la manera en la que el alumnado está acostumbrado a acatar esas palabras y a convertirlas en un conocimiento que no va más allá que la propia reproducción de ese saber concreto en un examen que más tarde olvidarán. A lo que también añadimos lo que Tomaz Tadeu da Silva rescata del concepto de "educación bancaria" de Freire:

La educación bancaria expresa una visión epistemológica que concibe el conocimiento como constituido por informaciones y hechos que el profesor simplemente debe trasferir al alumno. (...) En esta concepción, el conocimiento es algo que existe fuera e independientemente de los participantes del acto pedagógico. (Tadeo da Silva, 2001, p. 71)

$\mathrm{J}$ : "pienso que el arte y su pedagogía, puede ofrecernos no solo reflexividad sino otra manera de interpretar y movilizar a los estudiantes y a los profesores, permitiendo que emerjan nuevas maneras de comprender nuestra sociedad y nuestro posicionamiento en ella". 
3. Relato invisible:(Véanse las imágenes 4 y 8 de manera complementaria)

El relato invisible hace referencia a aquello que queda fuera de nuestras manos una vez las experiencias, las sensaciones y el conocimiento generado en el grupo queda expuesto. ¿Hacía dónde va ese conocimiento?¿De dónde ha venido? ¿En qué se convierte? ¿Cómo ha sido dado?

Los temas que se rescatan del relato invisible son:

- Miradas a los pequeños detalles importantes en el proceso de aprendizaje. Cuando la aparente comodidad puede transformarse en incomodidad y obstaculizar el proceso de aprendizaje.

- El relato en el que nos situamos puede modificarse a partir de la relación con los relatos de los Otros. Compartir la experiencia y darle significado, como estrategia para generar conocimiento.

R: “esta imagen me pareció una metáfora de la realidad escolar: no todo es lo que parece. En los centros educativos, damos por hecho que los contenidos del currículo y la manera de abordarlo son los correctos, pocas veces reparamos en las pequeñas grietas que hacen que nos sentamos incómodos o desprotegidos ante la realidad escolar".

E: "de esta 2. Sesión no me interesa tanto lo que sucedió dentro del aula. No podemos controlar en qué momento y de qué manera aprende cada individuo, pero sí que podemos ofrecer encuentros que permitan acompañar el aprendizaje. Si además consideramos que el conocimiento es el contenido/concepto que ponemos en circulación y compartimos con los Otros, un contenido que se lleva fuera del espacio donde aprendemos, y se traslada a otro contexto educativo".

$\mathrm{R}$ : "cuando $\mathrm{M}$ (docente de primaria) expuso su experiencia con su alumnado y compartió el método que utilizaba con ellos para que expresaran su opinión con el mayor respeto para con sus compañerxs de clase, vimos que era una manera interesante de acercarnos a las experiencias de los demás. Además el hecho de que una experiencia en un aula de primaria se convierta en conocimiento dentro de una comunidad de práctica y que a su vez este conocimiento genere una actividad práctica en las sesiones, indica que los conocimientos no se generan en una sola dirección. Es decir, nosotrxs que desde la universidad podemos ayudar o guiar a estos docentes en sus prácticas diarias, aprendemos nuevas maneras de comunicación, de entender al alumnado y de acercarnos a las personas con las que trabajamos". 
E: "Creo que cuando nos preguntamos sobre el conocimiento que generamos, este efecto rizomático del aprendizaje es la prueba de que el individuo ha hecho suyo el nuevo conocimiento trasladándolo a su propio contexto y generando una expansión de lo aprendido, de forma emocional además de cognitiva. ¿Dónde radica el conocimiento si no es en este efecto ramificador y de amplificación?".

El sentirse incómodo en un lugar donde se supone que tienes que sentirte seguro y confiado abre brechas para pensar, para investigar y sobre todo para cuestionarse. Y es que como dice Ellsworth (2005a) "cuando se rompen las suturas que mantienen la continuidad del envío y recepción de mensajes del diálogo comunicativo, cuando los límites de la comprensión y la persuasión se admiten, la posibilidad de lecturas "parciales", de "compresiones parciales" se abre".

Y estas lecturas parciales según Rooney (1989, p. 60) "afirman discontinuidades", sugiriendo que la persona que interrumpe en el diálogo comunicativo afirmando la discontinuidad puede "seguir a su deseo en alguna otra parte" (p. 59) y entrar en el proceso de interpretación desde un ángulo diferente, con otros propósitos en mente (Ellsworth, 2005, p. 113). Y eso es lo que pasa en este grupo. Los deseos o los conocimientos siguen hacia caminos no esperados, que regeneran el carácter del grupo y se transforman en otros saberes.

4. Trabajar lo relacional desde lo visual: (Véanse las imágenes 7 y 9 de manera complementaria)

Este apartado temático se centra concretamente en la última sesión del grupo, en la que a lxs participantes se les sugirió traer una imagen que los pudiera definir en sus prácticas profesionales. Para que después, desde la mirada que sus compañerxs les devolvían sobre su propia imagen, cuestionar la concepción de sí mismos nivel profesional y personal.

Los temas que aparecen dentro del trabajo desde lo visual son:

-La imagen, evocadora de emociones: en educación cada vez más a menudo se habla de educar en emociones, porque precisamente trabajamos con personas que sienten y no con objetos a modelar. La imagen permite acercarse a este campo desde una mirada interpretativa amplia y sugerente. Mucho más rica para abordar temáticas de la educación. 
E: "Esta sesión fue relevante porque utilizamos el foto-diálogo para hablar o pensar quienes somos como docentes. Por un lado me interesaba mucho trabajar desde lo visual, pero me movía intuitivamente. Para esta sesión decidí que los Otros comentarían la imagen desde la posición del VTS, centrándonos más en qué pensamos que puede estar sucediendo en esta imagen. Por otro lado, consideraba que escuchar lo que dicen de nosotrxs puede ofrecernos otra mirada y considerar hasta que punto lo que los Otros me dicen me configura."

Aunque algunos teóricos de los estudios visuales (Hodgetts et al. 2007) apuntan que la fotografía no tiene significados inherentes y que estos dependen del contexto en el que son vistos, nos parece interesante que el "significado de la fotografía sea de este modo más fluido y variable en respuesta a circunstancias cambiantes de la persona que fotografía, la persona que lo observa y lo que se está haciendo en la interacción entre estas dos personas" (Rose, 2012). En este caso se trataba de describirnos unxs a otrxs, para crear un conocimiento situado (en un espacio y en una acción en concreta) pero holístico a la vez, ya que lo que obtenemos es lo que unxs piensan de mí y lo que yo pienso de mi mismx en relación a mi práctica docente completando un reconocimiento mutuo.

R: "Comentaban lo que veían físicamente en ellas, lo que intuían detrás de las representaciones, lo que identificaban como parte de su identidad profesional... Fue un ejercicio interesante porque aparecieron relatos relacionados, ya que como comenta Rivas en 2014, en el encuentro con el otro mediante sus narraciones, se produce una modificación tanto de nuestra propia realidad como la del otro, lo que nos sitúa en el ámbito de las relaciones y sus implicaciones en la modificación de la realidad que construimos por medio de relatos".

Cuando damos por hecho las escenas, las experiencias y las sensaciones del día a día, se nos hace difícil reconocerlas como factores que nos constituyen en nuestras prácticas docentes. Ver estos factores en las imágenes de los demás nos hace cuestionar las nuestras propias, las mismas en las que no habíamos reparado antes y es que:

Art based reasearch is designed to enable readers and viewrs to see aspects of the social world that they might have overlooked otherwise. Engaging in arts based research text may thereby raise questions about conventional, commonsensical, orthodox ways of perceiving and interpreting the meaning of social phenomena. (Barone \& Eisner, 2012, p. 166). 
E: "Como dice Banks, M. (2010) facilita el dialogo con los Otros y permite establecer un diálogo evocador de emociones. Me llamó la atención que luego utilizara esta misma imagen como perfil suyo en el grupo en web de ARTikertuz, me resultó significativo y me lleva a pensar que lo que se dijo alimentó la imagen de sí mismo".

R: "las imágenes no siempre significan lo mismo para las personas, porque la información no está en ellas, sino en el conocimiento que construimos a partir de la relación con el otro. Y esto vuelve a su vez a recordarme el carácter regenerador del grupo".

\section{Conclusiones}

A modo de conclusión podríamos decir que acompañar el texto narrativo de imágenes ha hecho que nos centrásemos de manera significativa en las personas; incluso en aquellas imágenes en las que el aula estaba vacía, hacíamos alusión a las personas que ocupaban el aula; hemos dejado de objetualizar al sujeto investigado y le hemos permitido mostrarse/mostrarnos con las debilidades y fortalezas de los docentes que hacemos educación. Las palabras a veces nos llevan al mundo de las ideas donde las reflexiones pueden alejarse de situaciones cotidianas. El encuentro con el Otro sin embargo, nos hace rescatar la importancia y el valor del trabajo con personas, que quieren ser escuchadas y que desde el compartir aprenden.

Como nos dice Rivas (2014), en el encuentro con el otro mediante sus narraciones, se produce una modificación tanto de nuestra propia realidad como la del otro, lo que nos sitúa en el ámbito de las relaciones y sus implicaciones en la modificación de la realidad que construimos por medio de relatos.

Sentíamos haber perdido la fe en los grandes relatos o metarrelatos de la historia (Efland, Freedman, Sthur, 2003). Confiamos sin embargo, en una posición posmoderna constituida a partir de micro-relatos o micro-narrativas como el de las personas que estamos en el grupo ARTikertuz. Y, respondiendo a la pregunta de inicio: cuando nos preguntamos sobre el conocimiento que generamos, en el caso de este grupo hablaremos de aprendizaje rizomático que consideramos es la prueba de que el individuo ha hecho suyo el nuevo conocimiento trasladándolo a su propio contexto y generando una expansión de lo aprendido, de forma emocional además de cognitiva. ¿Dónde radica el conocimiento si no es en este efecto ramificador y de amplificación? 


\section{Referencias}

Acaso, M. (1998). La teoría de la elaboración como estrategia organizativa dentro del marco de la educación artística como disciplina, Arte, individuo y sociedad, 10, 65-176.

Acaso, M. (2014). rEDUvolution: hacer de la enseñanza una revolución. Barcelona: Espasa libros.

Banks, M. (2010). Los datos visuales en investigación cualitativa. Barcelona: Editorial Morata.

Barone, T y Eisner, E.W. (2012). Arts Based Research. USA: Sage.

Denzin, N. K. (1989). The Research Act (3 ${ }^{a}$ ed.) Englewood Cliffs. N.J: Prentice Hall.

Chrzanowska, J. (2002). Interviewing Groups and Individuals in Qualitative Market Research. Thousand Oaks, CA: Sage.

Connelly, M., Clandinin, D. J. (1995). Relatos de experiencia e investigación narrativa. En J. Larrosa (ed.), Déjame que te cuente. Ensayos sobre narrativa y educación. Barcelona: Laertes.

Correa, J.M., Aberasturi-Apraiz, E., Gutiérrez, L.P. (2015). Maestras de Educación Infantil: Identidad y cambio educativo. Bilbao: Universidad del País Vasco.

Efland, E., Freedman, K., Sthur, P. (2003). La educación en el arte posmoderno. Barcelona: Paidos.

Ellsworth, E. (2005). Posiciones en la enseñanza: diferencia, pedagogía y el poder de la direccionalidad. Madrid: Akal.

Ferrer, V. (1995). La crítica como narrativa de la crisis de formación. En J. Larrosa (ed.), Déjame que te cuente: Ensayos sobre narrativa y educación. Barcelona: Laertes.

Flick, U. (2004). Introducción a la investigación cualitativa ( $3^{a}$ ed.). Madrid: Ediciones Morata.

Gergen, K. (2006). Elyo saturado: dilemas de identidad en el mundo contemporáneo. Barcelona: Paidos.

Kvale, S. (2011). Las entrevistas en Investigación Cualitativa. Madrid: Ediciones Morata.

Padró, C. (2011). El aprendizaje de lo inesperado. Madrid: Libros de catarata. 
ABERASTURI, CORREA \& GUERRA / ARTikertuz, ¿qué conocimiento generamos a partir de la relación pedagógica entre profesorado?

Rivas, J.I., Herrera, D., Jiménez, R. Leite, A. (2014). Conocer la escuela a través de nuestras vidas. La biografía escolar como estrategia de aprendizaje. En A. García Valcárcel, Experiencias de innovación docente. Salamanca: Ediciones Universidad de Salamanca.

Rose, G. (2012). Visual Methodologies. Sage.

Tadeu da Silva, T. (2001). Espacios de identidad. Barcelona: Octaedro. 